\title{
ACTIVIDAD ANTAGONICA DE HONGOS ENDOFITOS DE PLANTAS MEDICINALES DEL ECUADOR SOBRE BACTERIAS PATOGENAS
}

\author{
(Antagonic activity of endophytic fungi from \\ medicinal plants of Ecuador on pathogenic bacteria)
}

\author{
Ramírez R. Jorge Yandry ${ }^{1}$, Ernesto Delgado Fernandez ${ }^{2}$, \\ Marinella Rodolfi ${ }^{3}$, Tosi Solveig ${ }^{3}$ \\ ${ }^{1}$ Centro de Biología Celular y Molecular, Universidad Técnica particular de Loja, \\ san Cayetano alto s/n. 1101 608, Loja-Ecuador. \\ ${ }^{2}$ Universidad Politécnica Salesiana Calle Vieja 12-30 y Elia Liut, Cuenca, Ecuador \\ ${ }^{3}$ Sezione di Micologia, Dipartimento di Ecologia del Territorio e degli Ambienti Terrestri, \\ Università di Pavia, via S. Epifanio 14, 27100, Pavia, Italy, solveig.tosi@unipv.it
}

Palabras Clave: Plantas medicinales, hongos endófitos, antagonismo, bacterias.

Keys words: Medicinal plants, Endophytic fungi, antagonism, bacteria.

\section{RESUMEN}

Mediante una investigación a lo largo del sector suburbano de la ciudad de Loja-Ecuador, dedicada al cultivo de plantas medicinales, se aíslaron los hongos endófitos asociados a Baccharis latifolia (Ruiz \& Pav.) Pers., Baccharis obtusifolia Kunth, Piper barbatum Kunth, Borreria laevis (Lam.) Grises, Chuquiragua jussieui J.F. Gmel y Bidens andicola Kunth. Los taxa fúngicos más frecuentes fueron: Alternaria, Aspergillus, Epicoccum, Fusarium, Nigrospora, Phoma, además de algunos representantes de los grupos: coelomycetes, sinnematosos y Zygomycota. La mayor dominancia fúngica correspondió a integrantes de los denominados «Mycelia sterilia», siendo de particular interés como posibles endófitos. Se evaluó además la interacción antagónica de siete aislados fúngicos frente a bacterias: Staphylococcus aureus, Klebsiella pneumomiae, Pseudomonas aeruginosa y Escherichia coli. La mayoría de las cepas fúngicas estudiadas presentaron actividad, pero los resultados más prometedores se evidenciaron en un aislado de «Mycelia sterilia».

\section{INTRODUCCION}

En la literatura analizada, no hemos encontrado datos sobre asociaciones de hongos endófitos en hojas de plantas ecuatorianas y en las utilizadas en este trabajo, existen sólo algunos antecedentes de hongos epífitos

\begin{abstract}
As a result of an investigation carried out along the suburban zone of the city of Loja-Ecuador, engaged in the growing of medicinal plants, endophytic fungi associated to Baccharis latifolia (Ruiz \& Pav.) Pers., Baccharis obtusifolia Kunth, Piper barbatum Kunth, Borreria laevis (Lam) Grises, Chuquiragua jussieui J.F. Gmel and Bidens andicola Kunth were isolated. Fungal taxa most frequently appearing were: Alternaria, Aspergillus, Epicoccum, Fusarium, Nigrospora, Phoma besides some representatives of the groups: coelomycetes, synnematous and Zygomycota. Major fungal dominance was found in elements of the so-called «Mycelia sterilia», which had a special interest as possible endophyte. Besides the antagonic interaction of seven fungal isolations in front of bacteria was assessed: Staphylococcus aureus, Klebsiella pneumomiae, Pseudomonas aeruginosa and Escherichia coli. Most of fungal strains investigated revealed activity, however most promising results could be seen in an isolation of «Mycelia sterilia».
\end{abstract}

asociados a diversas especies de Baccharis entre los cuales están: 22 especies de Ascomycota (19 géneros), 24 especies de Basidiomycota (18 géneros), 5 especies de hongos anamorfos (4 géneros) y 5 géneros de coelomycetes (Farr et al., 1995). Registros de la micota epífita se han reportado también para algunas especies de los géneros Piper y Borreria (Farr et al., 1995), pero faltan 
antecedentes sobre Piper barbatum, Borreria laevis, Baccharis latifolia y Baccharis obtusifolia.

Las especies vegetales utilizadas en este estudio han sido seleccionadas en base a dos principios: son nativas de la zona Andina del Ecuador y poseen propiedades medicinales y por tal motivo utilizadas por la población local que las cultiva (Bidlack et al., 2000; Aguirre, 2002; WHO, 2002; Villavicencio, 2006).

Zaragoza (2003) y Ordóñez \& Vega (2005), en el estudio etnobotánico de la «Planta de Productos Naturales», comentan los beneficios de las siguentes especies de interés medicinal analizadas en este estudio : Baccharis obtusifolia Kunth, vértigo, reumatismo y micosis de la piel, Borreria laevis (Lam.) Grises, para el espanto, en aplicación directa de sus hojas maduras machacadas, Piper barbatum Kunth, en dermatitis, como desinfectante y cicatrizante, Baccharis latifolia (Ruiz \& Pav.) Pers., como antiinflamatorio, cólico estomacal y cólico hepático, Chuquiragua jussieui J.F. Gmel, para resfriados, gripe, tos, dolor de huesos y Bidens andicola Kunth, contra la cefalea e insolación.

Los hongos en asociación endofítica con estas especies vegetales podrían jugar un rol importante en las propiedades medicinales de las mismas.

El propósito principal de esta investigación, fue aislar los hongos endófitos de estas 6 plantas ecuatorianas y determinar la interacción de los hongos aislados y las bacterias patógenas: Staphylococcus aureus, Klebsiella pneumomiae, Pseudomonas aeruginosa y Escherichia coli.

\section{MATERIALES Y METODOS}

Area estudiada. La investigación se llevó a cabo al sur del Ecuador, en la provincia de Loja, que limita al norte con las provincias de Azuay y El Oro, al este con Zamora Chinchipe, al sur y oeste con Perú, con una superficie de $11.027 \mathrm{~km}^{2}$ (Figura 1). La zona de estudio, esta localizada a lo largo del sector suburbano de la ciudad de Loja. La temperatura promedio anual es de $15.7^{\circ} \mathrm{C}$, y la precipitación media mensual es de 75,6 mm, con su máximo en los meses de febrero y marzo (INAMI 2006). El sector se encuentra dentro de las siguientes coordenadas: Longitud: $079^{\circ} 11,366 \mathrm{~W}$ hasta $079^{\circ} 11,893 \mathrm{~W}$, Latitud: $03^{\circ} 57,966$ S hasta $03^{\circ} 59,343$ S. Altitud: 2.125 hasta 2.144 msnm.

\section{Recolección y tratamiento de la muestra.}

Seis plantas ecuatorianas de interés medicinal: Baccharis latifolia, Baccharis obtusifolia, Piper barbatum, Borreria laevis, Chuquiragua jussieui y Bidens andícola, fueron colectadas desde sus áreas naturales. De cada planta seleccionada, se muestrearon diez individuos

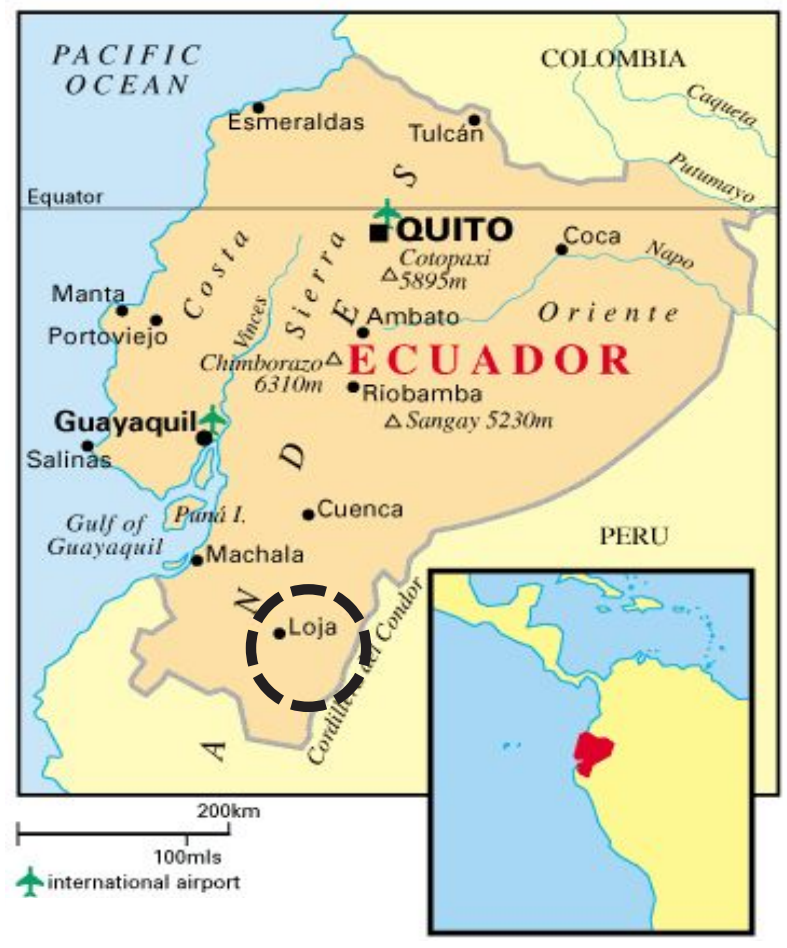

Figura 1: Localización geográfica de la Prov. de Loja.

diferentes y de cada uno se colectaron diez hojas al azar. Estas fueron puestas en bolsas de plástico estériles y llevadas al laboratorio para procesarlas en un período no superior a $24 \mathrm{~h}$ a partir del muestreo.

Las hojas se lavaron con agua potable y fueron esterilizadas superficialmente por inmersiones consecutivas, durante 1 minuto en etanol $70 \%(\mathrm{v} / \mathrm{v}), 10$ minutos en hipoclorito de sodio 3\% y 30 segundos en etanol 70\% (v/v), siguiendo el método reportado por Bills (1996). Para el secado de las hojas se dejó pasar unos minutos bajo la cabina de bioseguridad, cada hoja fue dividida en cuatro partes y mediante técnicas asépticas se cortaron en secciones pequeñas (3-5 $\mathrm{mm}^{2}$ ) entre la nervadura central y el borde de la hoja, con el uso de una tijera esterilizada con alcohol y flameada en el mechero.

Después de la esterilización, las secciones correspondientes a cada hoja se inocularon en cajas Petri $(100 \times 15 \mathrm{~mm})$ con Agar extracto de malta, (MEA; DIFCO). Las cajas se rotularon de acuerdo al código establecido (planta-individuo-hoja-muestra), e incubaron en el laboratorio a temperatura ambiente $\left(25 \pm 2^{\circ} \mathrm{C}\right)$ expuestas a períodos naturales de luz y oscuridad. Se inocularon un total de 40 fragmentos de hojas por especie vegetal. El crecimiento de las colonias se observó durante las primeras 2 semanas, luego se aislaron cada una de las nuevas colonias a cajas Petri $(60 \times 15 \mathrm{~mm})$ con agar extracto de malta y agar papa dextrosa (PDA) (Salgado \& Cerero, 2005). Los cultivos puros se rotularon y mantuvieron a 
tempera-tura ambiente $\left(25 \pm 2^{\circ} \mathrm{C}\right)$, expuestos a períodos naturales de luz y oscuridad.

\section{Evaluación de la interacción antagónica entre los aislados fúngicos y bacterias patógenas.}

Las bacterias patógenas fueron proporcionadas por la Planta de Productos Naturales de la Universidad Técnica Particular de Loja, las cepas con las que se evaluó la interacción fueron: Staphylococcus aureus subsp. aureus (ATCC Number, 25923), Klebsiella pneumoniae subsp. pneumoniae, (ATCC Number, 9997), Pseudomonas aeruginosa, (ATCC Number, 27853), Escherichia coli (ATCC Number, 25922). Las bacterias fueron inoculadas en cajas Petri (100 x 15 mm) con Tryptic Soy Agar (TSA; DIFCO), como medio de cultivo e incubadas a $37^{\circ} \mathrm{C}$, hasta observar crecimiento.

De la colonia fúngica crecida sobre PDA, se cortó y retiró con puntales estériles discos de micelio de $4 \mathrm{~mm}$ de diámetro. Estos fueron inoculados en cajas Petri de (100 mm), que contenían $20 \mathrm{ml}$ del mismo medio de cultivo, y a una distancia de 2, $6 \mathrm{~cm}$ del margen de la caja. A una distancia de $3.7 \mathrm{~cm}$ del disco fúngico recientemente inoculado, se colocó $0.5 \mathrm{ml}$ de suspensión (1 McFarland) de las bacterias patógenas $S$. aureus, K. pneumomiae, $P$. aeruginosa, o E. coli, en línea recta, tal como se indica en el esquema (Figura 2).

Cada prueba de antagonismo se repitió por triplicado, y al mismo tiempo se realizó un control del crecimiento bacteriano de las diferentes especies ensayadas. Las cajas fueron incubadas a $28^{\circ} \mathrm{C}$. La actividad inhibitoria por parte del hongo se consideró positiva cuando se verificó el crecimiento limitado o inexistente de la bacteria ensayada en dirección al hongo

\section{RESULTADOS Y DISCUSION}

Los taxa de hongos encontrados en las especies de plantas medicinales investigadas se observan en Tabla 1. El porcentaje referido a la incidencia del hongo en la planta, se calculó sobre el total de fragmentos de hojas analizados por especie vegetal (French \& Hebert; 1998).

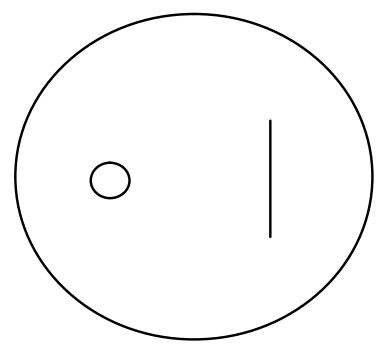

Figura 2. Esquema de la inoculación del hongo y las bacterias para el ensayo del antagonismo.
Los principales taxa aislados, fueron: Mycelia sterilia (micelios sin fructificaciones), Alternaria, algunos representantes de los coelomycetes y algunos hongos ambientales comunes (Acremonium, Epicoccum, Fusarium, Phoma) (Tabla 1), estos últimos se encuentran comúnmente en el aire como epifitos o en asociación con diversos sustratos (Barnett \& Hunter,1972; Domsch et al., 1980; Kiffer \& Morelet, 1997). Su presencia en las plantas analizadas podría ser indicativa de una colonización temporal eventual de los tejidos del hospedero, sin excluir un posible significado ecológico de endófitos (Carroll, 1986, 1988).

El hospedador con la mayor presencia y abundancia de endófitos fue Borreria laevis con 7 taxa, le siguen en importancia Chuquiragua jussieui y Piper barbatum (Tabla 1).

Algunos hongos aislados se consideran patógenos. Esto vale en particular para los géneros Alternaria y Fusarium, pues, se conoce su distribución cosmopolita, su habilidad fitopatogénica en diversos hospedadores no especie-específicos (tanto en plantas silvestres como cultivadas), la producción de micotoxinas, su oportunismo en el hombre y su rol endofítico (Sridhar \& Raviraja, 1995; Janardhanan \& Ahmad, 1997; Kuldau \& Yates, 2000; Rudgers et al., 2004; Rubini et al., 2005).

El grupo fúngico seguramente más interesante es el que corresponde a los micelios estériles. Estos se aislaron en todas las plantas medicinales investigadas (Tabla 1), seguidos por Alternaria spp. (presentes en 4 de los vegetales) y los colelomycetes (en 3). Por lo tanto, especialmente para los integrantes del primer grupo, podría existir un posible rol de asociación endofítica por su crecimiento solamente vegetativo en cultivos.

No fue posible asignarles una clara posición taxonómica a este grupo morfológicamente muy similar, debido a la falta de elementos sistemáticos y a su incompleto desarrollo en cultivos.

Los hongos endófitos derivan de un largo proceso de coevolución con sus hospederos vegetales, es por esto que puede ser muy difícil su aislamiento desde el hospedero vegetal (Espola, 2005). Una vez aislados, difícilmente se muestran fértiles in vitro. Petrini (1981), señala «...el factor más importante de inducción a la esporulación es el tiempo: aislados de endófitos pueden fructificar solo dos o tres meses luego de la inoculación y algunos requieren sobre los 12/14 meses...». El aislamiento de micelios estériles, es quizás uno de los resultados más interesantes de la presente investigación micológica, que necesita ser posteriormente analizado y que arroja una perspectiva muy amplia para el aislamiento de metabolitos secundarios, de interés potencial (Schulz, et al. 2002; Radu \& Kqueen, 2002; Agary et al., 2005). Revisiones recientes de la diversidad de metabolitos secundarios aislados de 
Tabla 1: Hongos encontrados en las seis especies de Plantas. El porcentaje esta referido a la incidencia del hongo en la planta calculada sobre el total de fragmentos de hojas analizados por especie de planta

\section{Ver Tabla 1 al final del artículo}

hongos endófitos enfatizan su favorable rol ecológico (Tan \& Zou, 2001).

\section{Pruebas de Interacción entre Hongos y Bacterias.}

Los resultados de la interacción antagónica de algunas de las cepas de hongos aislados que mostraron mayor actividad frente a bacterias patógenas, se presentan en la Tabla 2. Como una prueba de la acción de Mycelia sterilia, se consideró la cepa aislada de Baccharis obtusifolia, por su única presencia en este vegetal.

La mayoría de las cepas fúngicas analizadas, muestran actividad antibacteriana, en contra de Escherichia coli, Klebsiella pneumoniae, Pseudomonas aeruginosa y Staphylococcus aureus, sin embargo, la mayor actividad se detectó con Mycelia sterilia frente a Klebsiella pneumoniae (Tabla 2).

Se ha descrito en la literatura que los metabolitos secundarios fúngicos tienen una acción protectiva contra los insectos herbívoros en gramíneas y coníferas (entre otras) y un buen número de ellos son potenciales antimi-

Tabla 2: Interacción antogónica de algunas cepas fúngicas en bacterias patógenas

\begin{tabular}{|l|c|c|c|c|}
\hline $\begin{array}{c}\text { Taxa y } \\
\text { categorías } \\
\text { Fúngicas }\end{array}$ & $\begin{array}{c}\text { Escherichia } \\
\text { coli }\end{array}$ & $\begin{array}{c}\text { Klebsiella } \\
\text { pneumoniae }\end{array}$ & $\begin{array}{c}\text { Pseudomonas } \\
\text { aeruginosa }\end{array}$ & $\begin{array}{c}\text { Staphyloco- } \\
\text { ccus aureus }\end{array}$ \\
\hline Alternaria sp.1 & + & + & + & + \\
\hline Alternaria sp.2 & + & + & + & + \\
\hline Phoma sp. & + & + & + & + \\
\hline Nigrospora sp. & + & + & + & + \\
\hline Epicoccum sp. & + & + & + & + \\
\hline Mycelia sterilia & + & ++ & + & + \\
\hline Sinnematoso & + & + & + & + \\
\hline
\end{tabular}

Mycelia sterilia aislado de B. obtusifolia crobianos, motivo de nuestra búsqueda (Fisher et al, 1984; Stone \& Petrini, 1997; Picco \& Rodolfi, 2004). Resulta de interés considerar que dentro de los beneficios medicinales de algunas de los 6 vegetales analizados, se mezcla su acción analgésica, antiinflamatoria y antimicrobiana, donde los endófitos fúngicos podrían contribuir en sus efectos benéficos en la farmacopea popular.

\section{CONCLUSION}

Este reporte preliminar sobre la presencia de endófitos fúngicos en plantas del Ecuador consideradas medicinales en la farmacopea homeopática nacional, demostró que varias especies de hongos y especialmente los micelios estériles aislados, podrían constituir un óptimo y quizás inocuo material biológico para investigaciones futuras, en particular por la marcada actividad antagónica con los bacterias patógenas utilizadas.

\section{AGRADECIMIENTOS}

Un agradacemiento especial a la Prof. Anna Maria Picco de la Sección de Micología de la Università degli Studi di Pavia, al departamento de Biología Celular y Molecular de la Universidad Técnica Particular de Loja, por las facilidades en la presente investigación. Se agradece al MIUR por el financiamiento dado al Master Bienal Universitario Internacional de segundo nivel en «Scienza e Tecnologie per un utilizzo sostenibile delle risorse biologiche non tradizionali » en el proyecto de tipología a "Collaborazioni Interuniversitarie Internazionali (2001-2003 - prot. int01ad024)». 


\section{REFERENCIAS}

Agary, O.; Akinyosoye, F. \& Adetuyi, F. (2005). Antagonistic properties of microogranisms associated with cassaca (Manihot esculenta Crantz) products. African J. Biotechnol.. 4:627-632

Aguirre, Z. (2002). Botánica Austroecuatoriana. Ediciones Abya Yala, Quito, Ecuador.

Barnett, HL. \& Hunter, B. B. (1972). Illustrated Genera of Imperfect Fungi. Third Edition. American Phytopathological Society, USA

Bidlack, W.; Omaye, S.; Meskin, M. \& Thopham, D. (2000). Phytochemicals as Bioactive Agents. CRC press, New York.

Bills, GF. (1996). Isolation and analysis of endophytic fungal communities from woody plants. In «Endophytic Fungi in Grasses and Woody Plants» Redlin, S. C. \& Carris, L. M., APS Press, USA.

Carroll, G. (1986). The biology of endophytism in plants with particular reference to woody perennials. En: Fokema, N. J. \& Van den Heuvel, J. (eds.), Microbiology of the phyllosphere. Cambridge University Press, Cambridge.

Carroll, G. (1988). Fungal endophytes in stems and leaves: from latent pathogen to mutualistic symbiont. Ecology 69:2-9

Domsch, KH; Gams, W. \& Anderson, T. H. (1980). Compendium of soil fungi. Academic Press, London.

Espola, M. (2005). Catastro de hongos endófitos miceliales en Thrinax Morrisii h. wendl. en el bosque estatal de susúa, sabana grande, Puerto Rico. Universidad de Puerto Rico. Recinto Universitario de Mayagüez.

Farr, D. F.; Bills, G. F.; Chamuris, G. P. \& Rossman, A. Y. (1995). Fungi on plants and plant products in the Unites States. APS Press, USA.

Fisher, P.J.; Anson, A.E. \& Petrini, O. (1984). Antibiotic activity of some endophytic fungi from ericaceous plants. Bot. Helv. 94:249-253

French, E. \& Hebert, T. (1982). Métodos de Investigación Fitopatología. Costa Rica.

Kuldau, G. A. \& Yates, I. E. (2000). Evidence for Fusarium endophytes in cultivated and wild plants. In: Bacon .W., White J.F. (Eds.) Microbial Endophytes. Marcel dekker, Inc. New York-Basel.

INAMI (Instituto Nacional de Metereología e Hidrología). (2006). Resumen climatológico. Estación Base La Argelia.

Janardhanan, K. \& Ahmad, A. (1997). Fungal Endophytes of Grasses: Incidence and Distribution in India. Tropical Mycol. 157168.

Kiffer, E. \& Morelet, M. (1997). Les deutéromycètes classification et clés d'identification générique. Louis-Jean France.

Ordóñez, P, \& Vega, M. (2005). Estudio Fitoquímico de especies vegetales nativas utilizadas en la medicina tradicional de la Provincia de Loja. Tesis, Universidad Técnica Particular de Loja. Planta de Productos Naturales.
Petrini, O. (1981). Fungal endophytes of tree leaves. In: Andrews J.H., Hirano S.S. (Eds.) Microbial ecology of leaves. SpringerVerlag, New York, pp.179-197

Picco, A. M. \& Rodolfi, M. (2004). Endophytism in grasses with reference to an experience in Northern Italy. In: Ragazzi A., Moricca S., Dellavalle I. (eds.). Endophytism in Forest Trees. Accademia Italiana di Scienze Forestali. Tipografia Coppini, Firenze.

Radu, S. \& Kqueen, C. H. (2002). Preliminary screening of endophytic fungi from medicinal plants in Malaysia for antimicrobial and antitumor activity. Malaysian J. Med. Sc., 9:2333

Rubini, M.; Silva, R.; Pomilla, A.; Maki, C.; Araújo, W.; Santos, D. \& Azebedo, J. (2005). Diversity of endophytic fungal community of cacao (Theobroma cacao L.) and biological control of Crinipellis perniciosa, causal agent of Witches' Broom Disease. Int. J. Biol. Sci. 1:24-33

Rudgers, J.; Koslow, M. \& Clay, K. (2004). Endophytic fungi alter relationships between diversity and ecosystem properties. Ecology Letters 7:42-51

Salgado, C. \& Cerero, M. (2005). Aislamiento de hongos endófitos en rosa (Rosa hybrida) en Bogota, Colombia. Revista Iberoamericana de Micologia 22:99-101

Schulz, B.; Boyle, C.; Draeger, S.; Rommert, A. \& Krohn, K. (2002). Endophytic fungi: a source of novel biologically active secondary metabolites. Mycol. Res.106:996-1004

Sridhar, K. \& Raviraja, N. (1995). Endophytes- a crucial issue. Current Sci. 69:570-571

Stone, J. \& Petrini, O. (1997). Endophytes of forest trees: a model for fungus-plant interactions. In: The mycota $\mathrm{V}$ pàrt $\mathrm{B}$ Plant relationships (Carrol/Tudzynski eds.). Springer Verlag, Berlin Heidelberg. pp. 129-140

Tan, R. \& Zou, W. (2001). Endophytes: a rich source of functional metabolites. The Royal Society of Chemistry 18:448-459

Villavicencio, S. (2006). Diagnóstico de Enfermedades Fúngicas que afectan al follaje de ocho especies de Plantas Medicinales en la Parroquia de Chuquiribamba (Loja). Tesis, Universidad Técnica Particular de Loja. Laboratorio de Servicios Agropecuarios.

WHO (Word Health Organization) (2002). Medicina TradicionalNecesidades Crecientes y Potencial. Geneva.

Zaragoza, T. (2003). Estudio Entnomédico de las Plantas de las Provincias de Loja y Zamora - Chinchipe (Unpublished). FUNDACYT - Universidad Técnica Particular de Loja in: Project PFN 0133: Bioactividad de aceites esenciales y extractos de plantas medicinales y aromáticas de la región sur del Ecuador. 
Tabla 1: Hongos encontrados en las seis especies de Plantas. El porcentaje esta referido a la incidencia del hongo en la planta calculada sobre el total de fragmentos de hojas analizados por especie de planta

\begin{tabular}{|c|c|c|c|c|c|c|}
\hline Aislados fúngicos & $\begin{array}{c}\text { Borreria } \\
\text { laevis }\end{array}$ & $\begin{array}{c}\text { Baccharis } \\
\text { latifolia }\end{array}$ & $\begin{array}{c}\text { Baccharis } \\
\text { obtusifolia }\end{array}$ & $\begin{array}{c}\text { Bidens } \\
\text { andícola }\end{array}$ & $\begin{array}{c}\text { Chuquiragua } \\
\text { jussieui }\end{array}$ & $\begin{array}{c}\text { Piper } \\
\text { barbatum }\end{array}$ \\
\hline Acremonium sp. & & & & $\mathrm{X}(6 \%)$ & $\mathrm{X}(4 \%)$ & \\
\hline Alternaria sp.1 & $\mathrm{X}(20 \%)$ & $\mathrm{X}(10 \%)$ & & $\mathrm{X}(22 \%)$ & $\mathrm{X}(17 \%)$ & \\
\hline Alternaria sp.2 & $\mathrm{X}(70 \%)$ & $\mathrm{X}(30 \%)$ & & & & $\mathrm{X}(10 \%)$ \\
\hline Aspergillus sp. & & & & & & $\mathrm{X}(20 \%)$ \\
\hline Coelomycetes & & & & $\mathrm{X}(15 \%)$ & $\mathrm{X}(12 \%)$ & $\mathrm{X}(20 \%)$ \\
\hline Epicoccum sp. & $\mathrm{X}(10 \%)$ & & & & & $\mathrm{X}(10 \%)$ \\
\hline Fusarium equiseti & & & & $\mathrm{X}(24 \%)$ & & \\
\hline Fusarium sp. & & & & & $\mathrm{X}(17 \%)$ & \\
\hline Micelia sterilia & $\mathrm{X}(100 \%)$ & $\mathrm{X}(40 \%)$ & $\mathrm{X}(10 \%)$ & $\mathrm{X}(33 \%)$ & $\mathrm{X}(25 \%)$ & $\mathrm{X}(70 \%)$ \\
\hline Nigrospora sp. & $\mathrm{X}(10 \%)$ & & & & & \\
\hline Phoma sp. & $\mathrm{X}(10 \%)$ & & & & $\mathrm{X}(5 \%)$ & \\
\hline Stilbacea & $\mathrm{X}(10 \%)$ & & & & & \\
\hline Zygomycetes & & & & & & $\mathrm{X}(10 \%)$ \\
\hline
\end{tabular}

